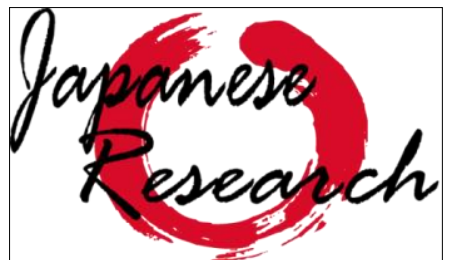

on Linguistics, Literature and Culture
Japanese Research on Linguistics, Literature, and Culture Vol. 2 No. 1 Nov. 2019, p., 60-76 ISSN Online: 2655-4836

DOI: $10.33633 /$ jr.vlil.3356

http://publikasi.dinus.ac.id/index.php/jrllc/article/view/3356/1835

japanese.research@fib.dinus.ac.id

Published by Universitas Dian Nuswantoro, Semarang

\title{
Tinjauan Sosiolinguistik Keigo dalam Manga de Manabu Nihongo Kaiwa Jutsu
}

\author{
Safitri Indah Kurniawati \\ SMK Perikanan Nusantara Demak \\ safitri.kurniawati@gmail.com
}

Article History: Submitted date 2019-11-27; Accepted date 2019-12-13; Published date 2019-12-26

\begin{abstract}
This paper discusses the use of Japanese keigo respectful types in terms of sociolinguistics. The purpose of this study was to determine the use of Japanese language respect in Nihongo Jaanaru in the Manga de Manabu chapter Nihongo Kaiwa Jutsu. This study uses data sources in the form of Nihongo Jaanaru in the chapter Manga de Manabu Nihongo Kaiwa Jutsu. In this study the discussion of the use of Japanese respect in the Nihongo Jaanaru chapter of the Manga de Manabu Nihongo Kaiwa Jutsu is examined using the distance theory framework proposed by Sachiko's Idea. This distance by Sachiko's idea is used to explain the sociolinguistic aspects of the Japanese respectful variety in Nihongo Jaanaru in the chapter Manga de Manabu Nihongo Kaiwa Jutsu. Based on the findings in the data analysis, the use of keigo is more emphasized on the distance of formality and psychological distance and keigo is used as respect and strategy to achieve the intended purpose.
\end{abstract}

Keywords: sociolinguistics, keigo, distance, honorific

\begin{abstract}
Abstrak
Tulisan ini membahas pemakaian ragam hormat bahasa Jepang keigo ditinjau dari segi sosiolinguistik. Tujuan penelitian ini adalah untuk mengetahui pemakaian ragam hormat bahasa Jepang dalam Nihongo Jaanaru pada bab Manga de Manabu Nihongo Kaiwa Jutsu. Penelitian ini menggunakan sumber data berupa Nihongo Jaanaru pada bab Manga de Manabu Nihongo Kaiwa Jutsu. Dalam penelitian ini pembahasan pemakaian ragam hormat bahasa Jepang dalam Nihongo Jaanaru pada bab Manga de Manabu Nihongo Kaiwa Jutsu dikaji dengan menggunakan kerangka teori jarak yang dikemukakan oleh Ide Sachiko. Jarak oleh Ide Sachiko ini digunakan untuk menjelaskan segi sosiolinguistik ragam hormat bahasa Jepang dalam Nihongo Jaanaru pada bab Manga de Manabu Nihongo Kaiwa Jutsu. Berdasarkan hasil temuan pada analisis data, pemakaian keigo lebih ditekankan pada jarak formalitas dan jarak psikologis dan keigo digunakan sebagai penghormatan dan strategi untuk mencapai maksud yang diinginkan.
\end{abstract}


Kata Kunci: sosiolinguistik, keigo, jarak, honorifik

\section{Pendahuluan}

Penelitian ini mengkaji ragam hormat bahasa Jepang "keigo", yaitu pemakaian ragam hormat bahasa Jepang ditinjau dari segi sosiolinguistik dengan sumber data Nihongo Jaanaru edisi tahun 2004 pada bab Manga de Manabu Nihongo Kaiwa Jutsu. "Keigo adalah ungkapan atau ekspresi hormat atau sopan Kinkuchi, (dalam Kusumo, 2001)". Di samping itu, "Keigo merupakan bahasa atau kata-kata yang khusus dipergunakan untuk menunjukkan kerendahan hati pembicara dan untuk menyatakan rasa hormat pembicara terhadap teman berbicara atau orang yang dibicarakan Minoru, (dalam Sudjianto 1996:124)". "Jenis-jenis ragam hormat bahasa Jepang berdasarkan cara pemakaiannya dibagi menjadi tiga jenis, yaitu sonkeigo (ragam menghormati), kenjougo (ragam merendahkan diri), dan teineigo (ragam sopan) Danasasmita, (dalam Sudjianto 1996:126)". Sonkeigo merupakan ragam hormat yang digunakan untuk menghormati mitra tutur, kenjougo merupakan ragam hormat yang digunakan untuk merendahkan diri di hadapan mitra tutur. Sedangkan teineigo merupakan ragam hormat yang digunakan untuk bahasa sopan.

Dengan adanya ragam hormat bahasa Jepang (keigo), memicu penulis untuk mempelajari pemakaiannya. “Orang Jepang pada saat berbicara selalu memperhatikan keadaan lawan bicara, misalnya, apakah lawan bicara itu orang yang baru dikenal ataukah orang yang lebih tua atau lebih tinggi status sosialnya dan atau sebaliknya (Mizutani,1987)". Dengan adanya pernyataan tersebut menunjukkan bahwa dalam bahasa Jepang terdapat ragam bahasa hormat dan penggunaannya harus disesuaikan dengan keadaan sosial masing-masing peserta tutur, keadaan sosial tersebut meliputi tingkat status, tingkat keakraban, atau bahkan tingkat keformalan suatu tuturan. Untuk itu penelitian ini mengangkat tema pemakaian ragam hormat bahasa Jepang ditinjau dari segi sosiolinguistik dengan sumber data Nihongo Jaanaru edisi tahun 2004 pada bab Manga de Manabu Nihongo Kaiwa Jutsu. 


\subsection{Sosiolinguistik Bahasa Jepang}

Kajian tentang kebahasaan tidak seluruhnya mempelajari bahasa secara murni, tetapi perlu diketahui bahwa kajian tentang kebahasaan juga mempelajari bahasa yang dihubungkan dengan kehidupan masyarakat pemakai bahasa tersebut. Kridalaksana (1978:94) menyatakan bahwa "Sosiolinguistik lazim didefinisikan sebagai ilmu yang mempelajari ciri dari pelbagai variasi bahasa, serta hubungan di antara para bahasawan dengan ciri fungsi bahasa itu di dalam suatu masyarakat bahasa itu". Dengan demikian, bidang-bidang yang diperlajari di dalam ilmu sosiolinguistik meliputi, variasi bahasa dan hubungan di antara para bahasawan kemudian juga mempelajari tentang hubungan bahasa dengan masyarakat pemakai bahasa.

Menurut Nakane (1988:9), “Masyarakat Jepang mempunyai kecenderungan untuk hidup dalam kelompok-kelompok sosial (social group)". Dalam pranata ini ditumbuhkan adanya kesadaran antar individu untuk menjalin hubungan timbal-balik. Kelompok sosial ini dapat berwujud kelompok profesi seperti institusi perusahaan, kantor ataupun institusi pendidikan. Hubungan individu dengan kelompok sosial tersebut telah dijadikan identitas sosial. Hal ini akan nampak ketika orang Jepang memperkenalkan diri kepada orang/kelompok lain yaitu dengan mengatakan bahwa "Saya dari perusahaan B/saya dari kantor C dan sebagainya". Identitas ini disandang untuk memberikan kekuatan moral seorang individu bila berhadapan atau sedang terlibat konflik dengan social group lainnya. Demikian pentingnya hal itu sehingga nama kelompok diberikan tempat untuk disebut pertama kali, selanjutnya barulah penyebutan pengenalan ciri-ciri pribadi. Berikut merupakan kutipan teori Nakane (1988:9) tentang social group.

Karakteristik perusahaan Jepang sebagai social group telah menciptakan suatu kesadaran (anggapan) bahwa perusahaan tersebut merupakan bagian dari keluarganya sendiri, baik individu yang bekerja pada perusahaan atau setiap keluarga yang bergabung secara intensif dalam perusahaan tersebut (Nakane, 1988:9).

Berdasarkan pernyataan tersebut menunjukkan bahwa orang Jepang merasa sangat bertanggung jawab terhadap perusahaan tempat mereka bekerja. Adanya pernyataan tersebut, tidak heran jika orang Jepang bersedia berjuang semaksimal mungkin demi perusahaan. Di dalam masyarakat Jepang juga terdapat sistem kemasyarakatan Jepang, berikut ini Lebra menjelaskan tentang sistem kemasyarakatan Jepang. 
Sistem kemasyarakatan di Jepang dapat dibedakan menjadi 2 kelompok yaitu kelompok uchi dan kelompok soto. Konsep uchi yaitu orang-orang yang sudah mempunyai hubungan dekat. Misalnya hubungan antarteman, antarkeluarga, antartetangga, hubungan dalam satu kelompok. Sedangkan konsep soto adalah orang-orang yang mempunyai hubungan yang tidak begitu dekat dengan orang lain. Misalnya hubungan dengan orang yang baru dikenal dan hubungan dengan kelompok lain. Sebagai contoh penerapan dalam sistem senpai-kohai, misalnya ada 2 kelompok belajar yaitu kelompok $\mathrm{A}$ yang terdiri dari senpai $\mathrm{A}$ dan kohai-kohai $\mathrm{A}$, dan kelompok B yang terdiri dari senpai B dan kohai-kohai B. Jadi, jika salah satu kohai A berinteraksi dengan kohai B atau senpai $\mathrm{B}$, maka hal tersebut disebut sebagai interaksi dengan pihak soto. Tapi jika salah satu kohai A berinteraksi dengan kohai A atau senpai A maka hal tersebut disebut sebagai interaksi antaruchi (Lebra, 1974:110-136).

Berdasarkan teori yang dikemukakan oleh Lebra (1974:110-136) dapat diketahui bahwa sistem kemasyarakatan Jepang terdiri dari kelompok dalam dan kelompok luar yang disebut dengan uchi dan soto. Orang Jepang juga sangat mengagungkan kesopanan dalam kehidupan sosial sehingga pemakaian ragam hormat bahasa Jepang disesuaikan dengan konteks sosial yang melatarbelakangi masyarakat Jepang. Adapun Ide Sachiko (1982 dalam Saifudin, 2005:18) mengungkapkan teori tentang kesopanan yang dimaknai sebagai 'jarak'. Kutipan teori tersebut adalah sebagai berikut.

Kesopanan dimaknai sebagai distance 'jarak' yang dirasakan oleh peserta tutur. Fungsi jarak disini dipahami sebagai konsep mendasar untuk mengontrol perilaku manusia dalam kesopanan. Jarak peserta tutur dilatarbelakangi oleh (1) jarak sosial berdasarkan kelas sosial, status, usia, dan kekuasaan (power), (2) formalitas, yang berdasarkan pada kurangnya pengetahuan peserta tutur, formalitas peristiwa atau topik, (3) jarak psikologis yang misalnya bergantung pada rasa hormat, avoidance 'penjauhan', kedekatan, dan solidaritas (Ide, 1982 dalam Saifudin, 2005:18).

Jika diperhatikan dari apa yang dikemukakan oleh Sachiko mengenai konsep jarak, jarak yang pertama berhubungan dengan jarak vertikal antarpeserta tutur kekuasaan (power), lalu jarak yang kedua berkaitan dengan situasi tutur, dan jarak yang ketiga berhubungan dengan jarak horisontal (solidaritas). Jarak tersebut berpengaruh terhadap ikatan dalam hubungan antarmanusia seperti yang dijelaskan oleh Nakane berikut ini.

Tipe pokok hubungan antarmanusia dapat dibagi-bagi menurut cara mengatur berbagai ikatan, menjadi dua kategori : vertikal dan horisontal. Hubungan anak dan orang tua 
adalah vertikal, hubungan antara saudara kandung adalah horisontal, hubungan antara atasan dan bawahan adalah vertikal, sedang hubungan antarrekan sejawat adalah horisontal (Nakane,1970:26).

Tipe pokok hubungan antarmanusia tersebut sangat berkaitan dengan konteks sosial yang menjadi latar belakang dalam masyarakat Jepang. Seperti yang diungkapkan oleh Nakane berikut ini merupakan latar belakang tipe pokok hubungan antarmanusia.

Di dalam kehidupan sehari-hari orang yang tidak sadar akan pangkat, relatif tidak akan dapat bicara, bahkan duduk dan makan. Bila berbicara ia diharapkan selalu siap dengan ungkapan-ungkapan penghormatan yang berbeda-beda dan menyenangkan, sesuai dengan susunan pangkat antara dia sendiri dengan orang kepada siapa ia berbicara. Ungkapan dan sopan santun yang cocok dihadapan atasan tidak boleh ditunjukkan di hadapan bawahan. Bahkan di antara rekan-rekan sejawat orang hanya bisa melepaskan diri dari kata dan tindak menghormati bila kedua-belah pihak sangat akrab saja. Adapun status, usia, popularitas, jenis kelamin merupakan unsur-unsur yang ikut menentukan penempatan seseorang, tetapi tanpa perkecualian, status merupakan faktor yang dominan. Usia dan jenis kelamin dalam hal ini kalah kuat bila dibandingkan dengan status. Sedangkan usia hanya merupakan faktor pembeda di kalangan orang yang memiliki status yang sama (Nakane, 1970:36).

Berdasarkan pendapat Nakane tersebut dapat diketahui bahwa orang yang tidak memahami pangkat merasa kesulitan pada pemakaian ragam hormat bahasa Jepang karena pemakaian ragam hormat tersebut berkaitan dengan pangkat. Terdapat aturan dalam pemakaian bahasa Jepang sehingga tidak boleh semena-mena memakai bahasa Jepang tanpa memperhatikan pangkat dari peserta tutur. Berikut Okamoto menjelaskan penggunaan keigo.

Penggunaan keigo adalah untuk mengungkapkan penghormatan dan/atau formalitas terhadap individu yang berhubungan referent (keterangan) dan/atau addressee (alamat tujuan) dan juga menegaskan kurangnya kedekatan/keakraban di antara peserta tutur. Namun, semua itu harus disesuaikan dengan konteks dan pertimbangan penutur mengenai tuturan yang digunakan (Okamoto, 1999 dalam Saifudin, 2005:19).

Berdasarkan teori yang diungkapkan oleh Okamoto dapat diketahui bahwa penggunaan non-honorifics tidak selalu menunjukkan tidak adanya rasa hormat, tetapi dapat berarti menunjukkan keakraban dan kurangnya formalitas sebuah konteks tuturan. Teori tersebut dihubungkan dengan teori yang dinyatakan oleh Lebra tentang situasi percakapan yang terdapat dalam masyarakat Jepang, sebagai berikut.

Ada tiga ranah situasi yang terjadi dalam interaksi, yakni intimate situation (situasi intim/akrab), ritual situation, dan anomic situation (situasi asing/tidak saling kenal). 
Faktor utama yang membedakan situasi satu dengan yang lain adalah adanya uchi dan soto. Uchi berarti "di dalam, internal, privat", soto berarti "di luar, eksternal, publik". Yang termasuk uchi adalah anggota keluarga, kelompok, sekolah, perusahaan, maupun negaranya, dan yang termasuk soto adalah orang-orang yang berada di luar kelompoknya atau orang asing. Sedangkan perilaku ritual biasanya terjadi dalam situasi ceremonial, situasi pada waktu rapat, atau dalam pekerjaan. Situasi ritual juga dapat terjadi dalam situasi yang seharusnya intimate. Biasanya situasi ini terjadi karena kehadiran orang ketiga. Contohnya adalah ketika suami istri yang seharusnya berperilaku intimate, mengubah menjadi perilaku ritual dikarenakan kehadiran anak, dengan tujuan agar anak belajar mengenai sopan santun (Lebra, 1976 dalam Saifudin, 2005:23).

Pada situasi intim, ego (penutur) menganggap bahwa alter (mitra tutur) sebagai orang dalam (insider) dan merasa yakin bahwa segala tindakan yang ditujukan kepada alter diperhatikan oleh orang ketiga (audience). Kebalikan dari situasi intim adalah situasi ritual, di mana ego merasa bahwa alter sebagai orang luar dan disadari bahwa ia bagaikan sedang memainkan peran di atas panggung yang disaksikan oleh alter maupun orang ketiga (audience). Tingginya kepercayaan diri yang terdapat pada situasi intim berkurang pada situasi ritual. Situasi anomik bertolak belakang dengan situasi intim. Pada situasi anomik, ego mengganggap alter sebagai orang luar dan tidak menunjukkan adanya keintiman di antara ego dan alter. Pada situasi anomik, ego terbebas dari perhatian orang ketiga (audience). Situasi anomik terjadi jika ego menganggap alter maupun orang ketiga (audience) sebagai orang yang tidak dikenal dan juga sebagai musuh. Situasi juga dapat berubah secara tiba-tiba dari situasi intim berubah menjadi situasi anomik, sebagai contoh, ketika terjadi pertengkaran dengan teman akrab sehingga teman akrab tiba-tiba menjadi musuh. Di samping itu situasi intim juga dapat berubah menjadi situasi ritual ketika kedatangan orang ketiga, sebagai contoh ketika suami istri yang seharusnya berperilaku intim, mengubah menjadi perilaku ritual karena kehadiran anak, dengan tujuan agar anak belajar mengenai sopan santun.

Lebra juga membagi perilaku interaksi sosial meliputi perilaku intim, perilaku ritual, dan juga perilaku anomik. Adapun pada perilaku intim, alter berasal dari lingkungan tempat tinggal, lingkungan pekerjaan, maupun lingkungan bermain. Pada perilaku intim tidak terdapat jarak di antara peserta tutur melainkan terdapat kesatuan, keutuhan, dan solidaritas. Situasi intim biasa dialami oleh pekerja yang menghabiskan waktunya di bar hanya sekedar untuk minum setelah bekerja bersama dengan rekan kerjanya. Situasi intim juga bisa terjadi pada saat santai seperti 
piknik, menginap di hotel, makan di restoran, di rumah teh, menyanyi, menari, dan situasi yang terbebas dari kerja. Bahkan tidur dan mandi bersama pun dengan orang yang sebaya juga menunjukkan perilaku intim. Hal tersebut dimaksudkan untuk mengurangi kejenuhan, kepenatan, atau bahkan menurunkan tekanan yang ada di dalam pikiran. Terdapat tindakan yang mencerminkan perilaku intim, yaitu sentuhan, dorongan, tamparan, dan rangkulan. Tindakan tersebut menunjukkan adanya kedekatan maupun keintiman di antara peserta tutur. Selain itu, di dalam perilaku intim ego tidak diharuskan menjalin komunikasi terhadap alter secara verbal karena sebelum diucapkan secara verbal pun alter sudah bisa menebak apa yang akan diucapkan oleh ego, komunikasi semacam ini disebut dengan komunikasi semitelepati atau ishin denshin (komunikasi dari hati ke hati).

Situasi ritual dapat mendatangkan perilaku ritual. Pada perilaku ini, ego menetapkan alter maupun orang ketiga sebagai outsider dan ada kesadaran bahwa perilakunya dinilai dan diperhatikan oleh alter atau orang ketiga sebagai audience. Perilaku ritual biasanya terjadi dalam situasi ceremonial, situasi pada waktu rapat, atau dalam pekerjaan. Perilaku ritual biasanya ditunjukkan adanya sikap tegang, menggunakan bahasa sopan dan formal, dan juga terdapat jarak antara ego dengan alter.

Kemudian pada perilaku anomik alter ditetapkan sebagai outsider. Tidak terdapat norma yang mengatur tindakan pada perilaku anomik. ego memperlakukan alter sebagai orang asing atau musuh sehingga ia tidak terlalu perlu memperhatikan norma-norma ego. Perilaku anomik terjadi pada saat ego berada dalam lingkungan baru dan ia merasa orang-orang tidak mengenalnya sehingga ia bebas bertindak sesuka hatinya. Perilaku anomik sering terjadi di stasiun kereta api, di mana orang-orang saling berebut memasuki kereta api, pada saat itu orang-orang tidak sadar atau bahkan lupa terhadap kesopanan dan martabat sehingga saling mendorong satu sama lain atau bahkan ada yang menarik orang lain keluar supaya ia bisa memasuki kereta api tersebut. (Matsumoto, 1996 dalam Saifudin, 2005:24) menyatakan bahwa "Secara psikologis orang Jepang akan merasa lebih dapat mengekspresikan emosinya di luar lingkungan sosialnya". 


\subsection{Keigo}

Dalam masyarakat Jepang status sosial dan hubungan keakraban bersifat mutlak dan sangat jelas dinampakkan dalam ragam hormat bahasa Jepang "keigo". Bagi orang Jepang sangat penting mengetahui bagaimana menentukan perbedaan status sosial dan keakraban dalam penggunaan keigo (Horikawa dan Hayashi, 1969 dalam Suherman, 2005:1).

Menurut Ishida, (dalam Suherman, 2005:1), “Keigo adalah salah satu ragam bahasa Jepang yang dipakai untuk mengungkapkan rasa hormat terhadap pendengar atau orang yang dibicarakan". Dalam kamus Renkai Shinkokugo Jiten, (dalam Suherman, 2005:1) tertulis “Keigo adalah ungkapan yang dipakai pembicara ataupun penulis untuk menyatakan perasaan hormat dan sopan terhadap lawan bicara, pembaca, dan orang yang dibicarakan". Sedangkan Minoru, (dalam Sudjianto, 1996:124) mendefinisikan keigo sebagai "Bahasa atau kata-kata yang khusus dipergunakan untuk menunjukkan kerendahan hati pembicara dan untuk menyatakan rasa hormat pembicara terhadap teman berbicara atau orang yang dibicarakan".

Berdasarkan berbagai pernyataan di atas, dapat diketahui bahwa keigo merupakan ungkapan hormat dari penutur untuk menyatakan perasaan hormat dan sopan terhadap mitra tutur, dan orang yang dipertuturkan. Pemakaian keigo tentu saja harus memperhatikan konteks sosial. Adapun konteks sosial tersebut meliputi tingkat status, tingkat keakraban, maupun tingkat keformalan suatu tuturan. Untuk itu, ancangan sosiolinguistik yang dipertimbangkan tepat sebagai alat pembahasnya.

\subsection{Jenis-Jenis Keigo}

\section{Sonkeigo}

Hiromi Hata, (dalam Sudjianto, 1996:128) mengatakan bahwa "Sonkeigo dipergunakan untuk menyatakan rasa hormat pembicara terhadap orang yang berbuat". Berdasarkan pernyataan tersebut, dapat diambil contoh sebagai berikut. Tamisan gorannasai irihi no rippana koto (Tami, lihatlah keindahan matahari yang terbenam itu!). Kata kerja gorannasai (melihat) digunakan untuk menghormati mitra tutur atas pertimbangan status sosial, usia, tingkat keakraban, dan sebagainya. Kata kerja gorannasai merupakan kata hormat atau kata halus dari kata kerja miru (melihat). 


\section{Kenjougo}

Kenjougo adalah tingkat tutur yang dipakai untuk merendahkan tindakan penutur (kerabat/keluarga), sehingga secara relatif menjunjung tinggi tindakan mitra tutur maupun orang yang dipertuturkannya (Hata, 1986 dalam Sudjianto, 1996:132). Tingkat tutur ini dipakai untuk "merendahkan" penutur bila berhadapan dengan mitra tutur dan atau sedang membicarakan orang yang dibicarakan. Seperti sonkeigo, tingkat tutur ini juga dapat hadir pada situasi formal maupun informal, yang salah satunya dipengaruhi oleh tingkat keakraban penutur dengan mitra tutur maupun dengan orang yang dipertuturkan tersebut.

\section{Teineigo}

Berdasarkan pemikiran Hata (dalam Suprihatnaningsih, 2002), teineigo tidak sama dengan sonkeigo atau kenjougo karena teineigo sama sekali tidak ada hubungannya dengan menaikkan atau merendahkan derajat orang yang menjadi pokok pembicaraan. Yang menjadi pertimbangan dalam teineigo hanyalah mitra tutur. Teineigo semata-mata dipergunakan untuk menghormati mitra tutur (person kedua). Jenis teineigo juga dapat dipergunakan kepada anggota keluarga yaitu dari anak kepada orang tua atau sebaliknya. Penggunaan jenis ini dalam keluarga dimaksudkan untuk saling memberi penghargaan antara sesama anggota keluarga. Selain itu, jenis teineigo juga dapat dipergunakan kepada orang yang baru saja kenal atau orang yang usianya lebih tua dari penutur atau dipergunakan untuk menunjukkan rasa saling menghargai antara sesama penuturnya tanpa melihat perbedaan usia, jenis kelamin atau status sosial antara penutur dan mitra tuturnya. Apabila penutur telah mengenal usia dan status sosial mitra tuturnya, ada kecenderungan jenis yang dipergunakan akan berubah. Penutur tersebut akan menggunakan sonkeigo atau kenjougo tergantung dengan siapa dia berhadapan. Contoh yang menunjukkan teineigo adalah Watashi mo okasan kara itsukatte kita no yo. Kyou no nuikono wa kata ga kottarou, okasan ga souiu kara, watashi tonde dekimashita. (Saya disuruh oleh ibu. Saya merasa pegal karena menjahit, sambil istirahat sebentar, saya mendengarkan nasihat ibu supaya besok bisa menjahit). Kata kerja dekimashita dimaksudkan untuk saling memberi penghargaan antara sesama anggota keluarga (watashi dan okasan). 


\section{Metode Penelitian}

Penelitian ini dilakukan melalui studi literatur. Data diperoleh dari sumber data Nohongo Jaanaru edisi tahun 2004 yang berupa percakapan pada bab "Manga de Manabu Nihongo Kaiwa Jutsu". Ancangan yang dipergunakan dalam penelitian ini adalah ancangan kualitatif. Ancangan kualitatif itu bersifat deskriptif, oleh karena itu dalam penelitian ini, peneliti mengambil data yang bersifat deskritif dengan cara mencatat secara teliti dan cermat data yang berwujud kata-kata dan kalimat-kalimat (Subroto, 1992:7). Penelitian ini studi sosiolinguistik yang berarti menganalisis tuturan tidak hanya dari segi bahasa, melainkan didasarkan juga pada konteks sosial masyarakat Jepang yang meliputi tingkat status peserta tutur, tingkat keformalan suatu tuturan, dan tingkat keakraban antarpeserta tutur.

\section{Hasil dan Pembahasan}

\section{Percakapan 1}

Data 1 mengenai "Adobaisu wo motomeru" (meminta nasihat) yang terdapat pada Nihongo jaanaru edisi bulan Februari tahun 2004, halaman 32. Konteks percakapan 1 terjadi di sekolah dan di luar jam pelajaran yang melibatkan Kimu berjenis kelamin laki-laki selaku murid dan sensei berjenis kelamin perempuan selaku guru sebagai peserta tutur. Di hari Valentine Kimu memperoleh cokelat dari temannya. Kimu bermaksud meminta saran kepada sensei mengenai balasan apa yang sebaiknya Kimu berikan kepada temannya, kemudian sensei menyarankan kepada Kimu supaya membalasnya dengan memberikan permen dan bunga. Kimu melaksanakan saran yang diberikan oleh sensei.

(1.1) Kimu

(1.1) Kimu

Sensei chotto yoroshi-i-desu-ka

Guru sebentar baik-non-past-TEI-Q

"Ibu, bolehkah minta waktunya sebentar?"

(1.2) Sensei

: Ara nani?
Lho apa-Q
"Lho, ada apa?"

(1.3) Kimu
: Barentain-no choko-no okaeshi-wa nani-wo Valentin-Gen cokelat-Gen balasan-non-past-Top apa-Acc agetara-ii-desu-ka.

memberi-baik-TEI-Q- Advise 
"Untuk membalas cokelat di hari Valentin, sebaiknya saya memberi apa ya Bu?"

(1.4) Sensei $\quad$ Kimu-san choko morat-ta-no.

Saudara Kimu cokelat menerima-past-Q
"Kimu menerima cokelat ya?"

Dalam konteks percakapan 1, peserta tutur ada dua yaitu Kimu dan sensei. Kimu adalah seorang murid berjenis kelamin laki-laki dan sensei adalah seorang guru berjenis kelamin perempuan. Dalam percakapan tersebut, berdasarkan teori Hata, keigo yang digunakan adalah teineigo. Berdasarkan teori yang dikemukakan oleh Hata, teineigo ditandai dengan adanya verba bantu masu dan desu. Ini diketahui pada penggunaan yoroshii desuka, agetara ii deshouka, semuanya diucapkan oleh Kimu sedangkan sensei menggunakan ragam biasa.

Berdasarkan data dapat diketahui bahwa pada jarak sosial, peserta tutur terdapat perbedaan status. Sensei berstatus sebagai guru sedangkan Kimu berstatus sebagai murid sehingga status sensei lebih tinggi dibandingkan dengan status Kimu. Pada jarak formalitas, konteks percakapan 1 tidak termasuk dalam situasi formal karena situasi tuturan terjadi di luar jam pelajaran. Sedangkan pada jarak psikologis, terdapat kedekatan antar peserta tutur karena antara sensei dengan Kimu termasuk hubungan dalam satu instansi yaitu sekolah sehingga termasuk dalam kelompok uchi. Dengan demikian, dapat diketahui bahwa pemakaian teineigo oleh Kimu terhadap sensei yang terdapat pada konteks percakapan 1 dititikberatkan pada jarak sosial yaitu adanya perbedaan status peserta tutur. Status Kimu sebagai murid lebih rendah dibandingkan dengan status sensei sebagai guru.

\section{Percakapan 2}

Data 2 mengenai "Yoyakusuru" (Membuat Janji) yang terdapat pada Nihongo Jaanaru edisi bulan Agustus tahun 2004, halaman 36.

Konteks percakapan 2 terjadi di salon kecantikan yang melibatkan Daniel berjenis kelamin laki-laki sebagai pengunjung salon dan pelayan salon berjenis kelamin perempuan sebagai pekerja di salon ALC Hair. Minggu depan saudara Kido akan melangsungkan upacara pernikahan. Untuk memperbaiki penampilannya Daniel pergi ke salon kecantikan untuk potong 
rambut. Tetapi sebelum pergi ke salon, Daniel memesan antrian potong rambut melalui telepon. Salon tersebut bernama ALC Hair. Daniel merupakan pengunjung baru sehingga belum memiliki nama pemotong rambut yang menjadi langganan di salon tersebut.

(2.1) Pelayan salon : Hai, hea aruku-degozai-mas-u.

Ya ALC hair-TEI-non-past

"Ya, ALC Hair".

(2.2) Daniel

: Ano, katto shitain-desu-kedo.

Anu potong ingin berbuat-non-past-TEI-Suf

"Saya ingin potong rambut".

(2.3) Pelayan salon : Go-yoyaku-desu-ne. Tantou-no go-shimei-wa

TEI-pesanan-TEI-Suf bagian-Gen TEI-nama-Top

Gozai-mas-u-ka.

ada-TEI-non-past-Q

"Mau pesan kan? Apakah sudah mempunyai pilihan

nama pemotong rambut di sini?".

(2.4) Daniel

: Et? Tantou? Go-shimei?

Apa? Bagian? TEl-nama?

Ano, hajime-te-nan-desu-kedo.

Anu pertama-Asp-TEI-Suf

"Apa? Pilihan pemotong rambut? Nama?

Saya baru pertama kali".

(2.5) Pelayan salon : A, shitsurei-itashi-mashi-ta.

O Apology-berbuat-KEN+TEI-past

Dewa, itsu-no go-yoyaku-desu-ka.

Perfik kapan-Gen TEI-pesanan-TEI-Q

"Mohon maaf, kapan Anda akan memesan?".

(2.5) Daniel

: Ashita-no 6-ji-wa ai-te-imas-u-ka.

Besok-Gen 6-jam-Top kosong-Asp-TEI-non-past-Q

"Apakah besok jam 6 ada waktu luang?"

Berdasarkan data dapat diketahui bahwa pada jarak sosial terdapat perbedaan status. Daniel berstatus sebagai pengunjung salon sehingga status Daniel lebih tinggi dibandingkan dengan status pelayan salon. Pada jarak formalitas, konteks percakapan 2 termasuk dalam situasi formal karena situasi tuturan terjadi di sebuah salon dan situasi sedang dalam pekerjaan yaitu pelayan salon sedang bekerja melayani Daniel. Jarak psikologis peserta tutur adalah jauh sehingga termasuk dalam kelompok soto karena Daniel dengan pelayan salon baru saja saling kenal. Dengan demikian, dapat diketahui bahwa pemakaian teineigo dan kenjougo+teineigo oleh Daniel terhadap pelayan salon maupun pelayan salon terhadap Daniel dititikberatkan pada 
jarak formalitas dan jarak psikologis. Dititikberatkan pada jarak formalitas karena situasi konteks percakapan 2 sedang dalam pekerjaan, yaitu pelayan salon sedang bekerja melayani Daniel sehingga situasi percakapan yang terjadi dalam konteks percakapan 2 adalah formal. Selain itu, dititikberatkan pada jarak psikologis karena Daniel dan pelayan salon termasuk dalam hubungan soto. Orang Jepang selalu memakai keigo terhadap orang yang baru saja dikenal.

\section{Percakapan 3}

Data 3 mengenai "Shouhin wo Torikaeru" (Menukarkan Barang) yang terdapat pada Nihongo Jaanaru edisi bulan November tahun 2004, halaman 38.

Konteks percakapan 3 terjadi di sebuah toko pakaian bayi, peserta tutur terdiri dari suami, istri, dan pelayan toko berjenis kelamin perempuan. suami dan istri sudah membeli pakaian bayi seharga $¥ 4980$ seminggu yang lalu, karena terdapat noda di pakaian tersebut maka suami dan istri kembali ke toko pakaian bayi tersebut untuk meminta ganti barang yang lebih baik. Pelayan toko meminta bukti pembayaran kepada suami dan istri, setelah memberikan bukti pembayaran, suami dan istri mendapat ganti barang yang lebih baik.

(3.1) Pelayan Toko

4980-En-ni nari-mas-u.

4980-yen-Dat menjadi-TEI-non-past

“Harganya ¥4980”.

(3.2) Istri

: Ano, kore isshuukan mae-ni kat-ta-n-desu-ga,

Anu ini seminggu depan-Dat membeli-past-TEI-Suf

koko-ni shimi-ga at-ta-n-desu-kedo,

di sini-Dat noda-Nom ada-past-TEI-Suf

torikae-te morae-nai-deshou-ka?

mengambil-non-past menerima-Neg-TEI-Q

"Saya membeli ini seminggu yang lalu, karena ada noda, bolehkah saya tukar dengan barang yang lebih baik?".

(3.3) Pelayan toko : Taihen moushi-wake-gozai-masen.

berat maaf-sebab-KEN+TEI-Neg-non-past

Reshiito-wa o-machi-deshou-ka?

Kuitansi-Top menunggu-KEN+TEI-Q

"Mohon maaf, apakah kuitansinya dibawa?".

(3.4) Istri : Ee.

ya 
"ya".

(3.5)

\begin{tabular}{|c|c|}
\hline Pelayan toko & : Atarashi-i mono-wo \\
\hline & Baru-non-past barang-Acc membawa-non-past \\
\hline & mairi-mas-u node, \\
\hline & pergi-KEN+TEI-non-past karena \\
\hline & shoushou o-machi-kudasai-mase. \\
\hline & sedikit menunggu-KEN+TEI-non-past-Imp \\
\hline & $\begin{array}{l}\text { "Silakan tunggu sebentar karena saya akan ambilkan } \\
\text { barang yang baru". }\end{array}$ \\
\hline
\end{tabular}

(3.6) Istri

: Ane-no kodomo-ni purezento shi-ta-n-da-kedo,

Kakak-Gen anak-Dat hadiah berbuat-past-Suf

kat-ta toki-wa shimi-ni ki-ga

Membeli-past waktu-Top noda-Dat hati-Nom

tsuka-na-kute.

menempati-Neg-non-past

"Saya ingin memberikan ini sebagai hadiah kepada anak

kakak, tetapi pada waktu membeli saya tidak sadar

kalau terdapat noda di baju".

(3.7) Suami

: Oneesan-ga irun-da...

Kakak-Nom ada-non-past

"Apakah punya kakak?"

(3.8) Pelayan toko

\section{O-matase itashi-mashi-ta. \\ Menunggu-non-past berbuat-KEN+TEI-past \\ Kochira-de yoroshi-i-deshou-ka? \\ Ini-TEI-Con baik-non-past-TEI-Q \\ "Maaf telah menunggu. Apakah ini sudah cocok?".}

(3.9) Istri

: Hai, ariga-tou gozai-mas-u.

Ya terima kasih-KEN+TEI-non-past

"Ya, terima kasih".

Berdasarkan percakapan antara suami kepada istri dapat diketahui bahwa pada jarak sosial, suami dan istri terdapat perbedaan status dan jenis kelamin yaitu status suami lebih tinggi dibandingkan dengan status istri. Pada jarak formalitas, situasi percakapan antara suami kepada istri adalah tidak formal. Berdasarkan teori yang dikemukakan oleh Ide Sachiko, (1982 dalam Saifudin, 2005:18), jarak psikologis suami dan istri termasuk dekat. Berdasarkan teori yang dikemukakan oleh Lebra, (1974:110-136), tentang sistem kemasyarakatan di Jepang, 
hubungan suami dan istri termasuk hubungan dalam satu kelompok sehingga temasuk dalam kelompok uchi terhadap pelayan toko. Pemakaian ragam biasa dalam percakapan antara suami dan istri pada nomor urut percakapan (3.6) dan (3.7) dititikberatkan pada jarak formalitas dan jarak psikologis. Dititikberatkan pada jarak formalitas karena situasi percakapan antara suami dan istri bersifat tidak formal. Selain itu, dititikberatkan pada jarak psikologis karena jarak psikologis antara suami dan istri termasuk dekat sehingga termasuk dalam kelompok uchi. Dengan demikian, pemakaian ragam biasa dalam percakapan antara suami dan istri pada nomor urut percakapan (3.6) dan (3.7) dititikberatkan pada jarak formalitas dan jarak psikologis.

Berdasarkan percakapan antara suami dan istri dengan pelayan toko dapat diketahui bahwa pada jarak sosial, terdapat perbedaan status antara suami dan istri dengan pelayan toko. Status suami dan istri sebagai pengunjung toko lebih tinggi dibandingkan dengan status pelayan toko. Pada jarak formalitas, situasi pada konteks percakapan antara suami dan istri dengan pelayan toko adalah formal karena situasi percakapan sedang dalam pekerjaan yaitu pelayan toko sedang bekerja melayani suami dan istri. Pada jarak psikologis, hubungan suami dan istri dengan pelayan toko adalah jauh sehingga termasuk dalam kelompok soto karena mereka baru saja saling kenal. Dengan demikian, dapat diketahui bahwa pemakaian teineigo dan kenjougo + teineigo oleh suami dan istri terhadap pelayan toko maupun pelayan toko terhadap suami dan istri dititikberatkan pada jarak formalitas dan jarak psikologis. Dititikberatkan pada jarak formalitas karena situasi konteks percakapan 3 sedang dalam pekerjaan, yaitu pelayan toko sedang bekerja melayani suami dan istri sehingga situasi percakapan yang terjadi dalam konteks percakapan 3 adalah formal. Selain itu, dititikberatkan pada jarak psikologis karena antara suami dan istri dengan pelayan toko baru saja saling kenal sehingga jarak psikologis mereka adalah jauh dan termasuk dalam kelompok soto. Orang Jepang selalu memakai keigo terhadap orang yang baru saja dikenal.

Berdasarkan analisis data nomor urut percakapan (3.9), pemakaian kenjougo berupa arigatou gozaimasu oleh suami dan istri terhadap pelayan toko menunjukkan bahwa suami dan istri mempunyai tujuan tertentu terhadap pelayan toko sehingga suami dan istri memakai kenjougo sebagai sebuah strategi untuk menyampaikan suatu tujuan tertentu. Adapun tujuan 
tersebut adalah suami dan istri bertujuan mengucapkan terima kasih terhadap pelayan toko atas kebaikan yang diberikannya yaitu bersedia menukar baju yang terkena noda dengan baju yang baru. Sebuah tujuan tersebut mampu mengubah status suami dan istri menjadi rendah di hadapan pelayan toko sehingga suami dan istri memakai kenjougo berupa arigatou gozaimasu dengan maksud merendahkan dirinya di hadapan pelayan toko.

\section{Simpulan}

Berdasarkan hasil analisis data, pemakaian keigo pada sumber data dititikberatkan pada jarak formalitas dan jarak psikologis dari pada jarak sosial. Penekanan pada dua hal ini ditemukan pada 4 konteks percakapan. Sedangkan status hanya pada konteks percakapan 1. Pada jarak formalitas, empat percakapan terjadi dalam situasi pekerjaan, yaitu pelayan salon dan pelayan toko. Pada jarak psikologis, keigo yang digunakan terjadi pada peserta percakapan yang hubungannya termasuk dalam sotomono.

Peran jarak sosial pada penggunaan keigo tidak selalu dapat dijadikan tolok ukur. Berdasarkan data yang sudah dianalisis terdapat pemakaian keigo (kenjougo) yang dituturkan oleh penutur dengan status lebih tinggi kepada mitra tutur dengan status lebih rendah. Dalam situasi ini, berdasarkan analisis data diketahui bahwa penggunaan keigo tersebut karena adanya suatu maksud tertentu. Jadi keigo dijadikan "strategi" supaya maksud yang dinginkan tercapai.

Berdasarkan analisis data pada penelitian ini dapat diketahui simpulan secara umum, pemakaian keigo pada sumber data tersebut yaitu untuk menghormati dan untuk dijadikan "strategi" supaya maksud yang diinginkan oleh penutur dapat tercapai. Penekanan keigo pada jarak formalitas dikarenakan percakapan terjadi dalam situasi pekerjaan, yaitu pelayan salon dan pelayan toko. Penekanan keigo pada jarak psikologis karena hubungan peserta percakapan termasuk dalam sotomono.

\section{Referensi}

Bunkachou. 1985. Kotoba Shiriizu-keigo. Ookurashou Insatsu Kyoku. Tokyo. Danasasmitha, Wawan \& Sudjianto. (1985). Pengantar Tata Bahasa Jepang. BSC. Bandung. Fishman, J.A. (1972). The Sosiologi Of Language. Rowly-Masschusett: Nwebury House. 
Ganda, Erick. (2007). Penerapan Sistem Senpai-Kohai dalam Mendidik Siswa Sekolah di Indonesia. Karya Tulis Mahasiswa. Semarang : Universitas Dian Nuswantoro.

Hata, Hiromi. (1986). Keigo o Tanoshiku Tsukaikonasu. Nihongo Jaanaru, ALC Press. Tokyou.

Horikawa Tadayoshi \& Hayashi Shiro. (1977). Keigo Gaido. Tokyou :Meiji Shoin.

Hymes, Dell(Ed). (1964). Language in Culture and Society. New York: Harper and Row.

Ide, Sachiko. (1982). "Japanese Sociolinguistics : Politenes and Women's Language", dalam Lingua 57. (366-377).

Ishida, Noriko, dkk. (1991). Keterangan Tatabahasa Dasar-dasar Bahasa Jepang. Yogyakarta: PPSI-FIB-UGM.

Kinkuchi Yasuto. (1994). Keego. Kadokawarekigen, Japan.

Kitao, K. (1989). Differences Between Politness Strategies Used in Requests by Americans and Japanese. Dalam K. Kitao and S.K. Kitao. (eds). Intercultural Communication : Between Japan and the United States (hal 139-154), Tookyoo :Eichosa Shinsha.

Kridalaksana, Harimurti. (1983). Kamus Linguistik. Penerbit PT. Gramedia, Jakarta.

Lebra, Takie Sugiyama dan Lebra, William P. (1974). Japanese Culture and Behavior. Honolulu : The University Press of Hawaii.

Lebra, Takie Sugiyama. (1976). Japanese Patterns of Behavior. Honolulu : The University Press of Hawaii.

Leonie, Agustina \& Chaer, A. (1995). Sosiolinguistik Suatu Pengantar. Jakarta : PT Rineka Cipta.

Matsumoto, David. (1996). Unmasking Japan : Myths and Realities about the Emotions of the Japanese.

Minoru, Nishio. (1986). Kokugo Jiten. Iwanami Shouten, Tokyou.

Mizutani, Osamu dan Mizutani, Nobuko. (1978). How to be Polite in Japanese, Tokyo: The Japan Times.

Nababan, P.W.J.(1984). Sosiolinguistik: Suatu Pengantar,Jakarta Gramedia.

Nakane, Chie. (1970). Masyarakat Jepang. Jakarta : Sinar Harapan.

Nakane Chie. (1998). Inside the Japanese System: Reading on Contemporary, Society and Political-Economi. Stanford University Press.

Okamoto, Shigeko. (1999). "Situated Politeness : Manipulating Honorific and Non-Honorifics Exprssions in Japanese Conversations" dalam Pragmatics 9:1,51-74, International Pragmatics Association.

Puspito Kusumo. (2001). Perbandingan Keigo dan Krama dalam Kajian Sosiolinguistik. Skripsi S1. Yogyakarta : PSSJ-FIB-UGM.

Saifudin, A. (2018). Konteks dalam Studi Linguistik Pragmatik. LITE: Jurnal Bahasa, Sastra, dan Budaya, 14(2), 108-117.

Saifudin, Akhmad. (2008). Analisis Fungsi Pragmatik Tindak Tutur Pertanyaan dalam Percakapan Bahasa Jepang antara Wisatawan Jepang dan Pemandu Wisata Indonesia di Candi Borobudur. LITE: Jurnal Bahasa, Sastra, dan Budaya, 4 (1), 8-15.

Saifudin, Akhmad. (2005). Faktor Sosial Budaya dan Kesopanan Orang Jepang dalam Pengungkapan Orei no Kotoba. Laporan Penelitian. Semarang: Universitas Dian Nuswantoro.

Subroto, E. (1992). Pengantar Metode Penelitian Linguistik Struktural. Surakarta : Sebelas Maret University Press.

Sudjianto. (1996). Gramatika Bahasa Jepang Modern, Cetakan I, Kesaint Blanc, Jakarta. 